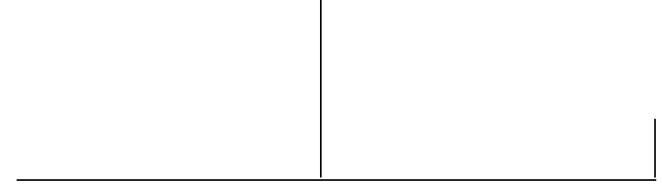

Rev. Latinoam. Psicopat. Fund., VII, 1, 97-105

\title{
0 que (não) esperar das classificações diagnósticas em psiquiatria
}

\author{
Cláudio E. M. Banzato
}

It may be argued that psychiatry has more need of ombudsmen than most other branches of medicine since its pretensions are greatest and its foundations least secure.

M. Shepherd, 1986

As revisões periódicas (com intervalos variáveis) das classificações diagnósticas em psiquiatria costumam despertar grande interesse profissional, uma vez que impõem naturalmente, como ponto de partida, um balanço de suas conquistas, fracassos e impasses; além disso, ao fim e ao cabo, tais processos determinam, em maior ou menor grau, os rumos da disciplina. Como diferentes tradições intelectuais continuam a conviver na psiquiatria atual, fato que ocorre desde os seus primórdios e que, aliás, é tido como uma de suas marcas registradas, não é de se estranhar que o início dos trabalhos de revisão seja marcado por uma intensa atividade política e que o estabelecimento dos comitês diretores e forças-tarefa, mais o planejamento cuidadoso das ações, possam consumir alguns anos. Assim, posto que neste momento nos encontramos (depois de um lapso mais longo que o habitual) numa fase preliminar de preparação para a revisão dos sistemas CID-10 (Organização Mundial da Saúde) e DSM-IV (Associação Psiquiátrica Norte-americana), julgo ser 
apropriado comentar, ainda que brevemente, tópicos selecionados da literatura recente sobre o assunto, procurando indicar alguns dos principais dilemas e falsos problemas colocados, com o intuito de apresentar ao leitor não especialista pontos específicos do debate. Este é o objetivo das esquemáticas observações subseqüentes.

O primeiro tópico a ser considerado diz respeito à importância relativa das classificações diagnósticas para a psiquiatria. Não raramente constatamos que profissionais da área se queixam de que sistemas diagnósticos baseados em critérios explícitos e observáveis, como o DSM-IV e o capítulo V da CID-10 (dedicado aos transtornos mentais), conformam em demasia a prática clínica da especialidade, estabelecendo regras para assegurar a legitimidade dos procedimentos que têm lugar no contexto do encontro clínico, legislando enfim sobre as bases estritas nas quais a clínica supostamente deveria repousar. Curiosamente, é interessante notar que tais manifestações, em geral, vêm acompanhadas de críticas à falta de relevância clínica dos mesmos sistemas. Não é difícil, entretanto, conciliar os dois aspectos mencionados: é como se, em tese, a prerrogativa dos sistemas de determinar a clínica fosse aceita, mas seus resultados (modelos e propostas), ficassem muito aquém das expectativas dos profissionais. Ora, é possível sugerir uma outra leitura do fenômeno. Não haveria, porventura, uma certa superestimação do poder das classificações, associada à percepção de que tais instrumentos são, via de regra, utilizados de maneira ingênua, isto é, sem o necessário entendimento dos papéis desempenhados pelos mesmos? Talvez a questão crucial seja compreender o que realmente deve ser esperado de qualquer classificação diagnóstica, qual o seu lugar de direito no arcabouço teórico dessa disciplina, quais as suas múltiplas funções e propósitos e, last but not least, quais as formas de apropriação indevida e usos retóricos, para fins os mais variados, a que tais classificações são muitas vezes submetidas.

Existe uma íntima ligação entre o desenvolvimento dos sistemas classificatórios nas últimas três décadas e a busca de uma ancoragem científica para a psiquiatria, especialidade médica que já enfrentou, no passado, diversas crises de legitimidade. As razões para os questionamentos da psiquiatria fogem ao objetivo deste artigo, mas podemos afirmar que elas variaram ao longo do tempo, embora sempre girando em torno da influência de valores sociais na delimitação do seu objeto (os transtornos mentais), dos contornos pouco precisos do mesmo, das infindáveis disputas no interior da disciplina, da sua problemática articulação com o corpo de conhecimento da medicina, dos modismos diagnósticos a que freqüentemente sucumbe e da suposta arbitrariedade de algumas de suas intervenções. Assim, o dilema colocado desde sempre para a psiquiatria é mais ou menos o seguinte: como ser científica, sem deixar de ser psiquiatria? Como organizar o campo psiquiátrico de modo a permitir pesquisas 
metodologicamente rigorosas e como aproveitar clinicamente seus resultados são perguntas que traduzem bem esse desafio. A aposta mais recente da psiquiatria nesse sentido foi a do estabelecimento de uma unificadora 'linguagem comum', tida como condição para a replicabilidade dos estudos. A nomenclatura que deveria fazer as vezes dessa linguagem comum proviria das classificações diagnósticas, baseadas em critérios explícitos.

A questão “por que classificar?” em ciência não é difícil de ser respondida: classificamos para ordenar ou dispor objetos em grupos, o que nos permite manipular mais facilmente os conjuntos de informações resultantes, inclusive para fins de comunicação. Outra questão correlata, “como classificar?”, no entanto, é bem mais complexa, pois a escolha da estratégia classificatória não deixa de revelar certos pressupostos sobre a "natureza" do objeto classificado. Além disso, afora as funções pragmáticas referidas, as classificações também cumprem um papel significativo no desenvolvimento teórico de um campo: um sistema classificatório representaria um tipo especial de formação de conceito científico. Em outras palavras, espera-se que o arranjo operado por uma classificação contribua, outrossim, para a plena enunciação de uma teoria e, conseqüentemente, para a geração de novas hipóteses. Portanto, a questão da "correção" de uma dada classificação diagnóstica (isto é, de sua validade nosológica), é de difícil resolução, pois depende da elucidação da natureza dos transtornos mentais.

A reconhecida heterogeneidade das condições admitidas sob a rubrica de “transtornos mentais”, agravada pela expansão contínua das categorias diagnósticas psiquiátricas, é evidentemente um entrave para quem se propõe a definir transtorno mental por meio da busca de um denominador comum entre todos os quadros listados nos sistemas classificatórios. Mas essa não é uma dificuldade específica da psiquiatria, o mesmo vale para a medicina em geral; no entanto, a falta de uma definição consensual de doença nunca foi obstáculo para a identificação de novas condições mórbidas. As doenças são classificadas por princípios que diferem amplamente entre si e, muitas vezes, estas ainda trazem no nome as concepções nosológicas da época em que foram inicialmente descritas. Por outro lado, é interessante notar que, usualmente, não nos valemos de qualquer definição geral de doença para decidir se uma dada condição deve ou não ser considerada mórbida. Em resumo, não construímos indutivamente uma definição de doença ou de transtorno mental com base nas instâncias dos mesmos, mas tampouco partimos dedutivamente de uma definição geral para verificar se uma determinada condição qualifica ou não como doença ou transtorno mental (Pouncey, 2003). Assim, se uma definição de transtorno mental importa muito para a delimitação do campo da psiquiatria e para o debate em torno de sua legitimidade social, ela não parece ser de todo indispensável para efeito da elaboração de uma classificação diagnóstica, caso dos sistemas atuais. Todavia, ainda precisa ser 
estabelecido em que medida os defeitos da CID-10 e do DSM-IV decorrem da adoção de uma definição "frouxa” de transtorno mental por parte dos dois sistemas.

É interessante notar que duas percepções opostas sobre as conseqüências do problema da delimitação e da identificação dos transtornos mentais coexistem: por um lado, parte dos profissionais (e do público leigo) manifesta uma preocupação com o excesso de diagnósticos psiquiátricos e com a crescente inclusividade dos mesmos, que cada vez mais abarcariam as dificuldades e sofrimentos cotidianos enfrentados pela humanidade; por outro lado, alguns especialistas se ressentem do fato dos diagnósticos dependerem de relatos subjetivos e queixas dos pacientes, bem como da observação (não de todo confiável) dos profissionais. Enquanto para os primeiros o problema reside nos casos de "falso positivo", para os últimos o principal temor é de que os transtornos passem despercebidos (casos de "falso negativo") e, por essa razão, estes anseiam por testes objetivos (provenientes das neurociências e da genética) que se constituiriam então no padrão ouro do diagnóstico psiquiátrico (cf. Hyman, 2003). No limite, tais modelos biológicos dispensariam, por obsoleta, a psicopatologia como a conhecemos. Em vez de uma análise sistemática da experiência subjetiva, teríamos como ponto de partida aquelas configurações neurofisiológicas, cognitivas e comportamentais que apresentassem um padrão de transmissão genética melhor definido. ${ }^{1}$ Nesse cenário, o sintoma perderia sua centralidade. É sempre bom lembrar que o fascínio exercido pelas promessas da objetividade nos psiquiatras tem sido uma constante na história da disciplina. ${ }^{2} \mathrm{E}$ para saber a que ponto tal fascínio deitou raízes, basta descobrir o que os psiquiatras estão dispostos a sacrificar em nome da sonhada objetividade.

Um dos pontos mais vulneráveis das classificações atuais é a inflação provocada pelas mesmas das taxas de comorbidade, o que de certa forma termina por se contrapor à aparente arrumação de suas categorias diagnósticas. $\mathrm{O}$ fato dos sintomas psiquiátricos serem bastante inespecíficos e flutuantes ao longo do tempo torna problemática e, em certa medida, arbitrária a separação conceitual e prática dos transtornos. Isso é ainda mais acentuado na ausência de uma hierarquia entre os transtornos. Claro que justificativas pragmáticas podem induzir à aceitação de maiores taxas de comorbidade, um bom exemplo disso é a

1. Para uma crítica dessa posição, cf. Jablensky (1999).

2. Em psiquiatria, objetividade tem um claro sentido de fundamentação biológica, correspondendo ao que Jaspers, na Introdução de Psicopatologia Geral, chamou de preconceito somático, assim traduzido por ele: "Conhece-se o homem quando se conhece somaticamente. Falar do psíquico é um recurso provisório e significa apenas um sucedâneo sem valor próprio de conhecimento” (Jaspers, 1987). 
ampliação do foco de atenção clínica. A rigor, nada há de errado nessa abordagem, desde que suas limitações sejam reconhecidas. No entanto, curiosamente o que se observa com freqüência é algo bem diverso: artefatos (como, por exemplo, boa parte das comorbidades), que antes deveriam ser tomados como razão de humildade, sendo exibidos orgulhosamente como triunfos empíricos de uma disciplina que, tendo superado suas antigas deficiências, finalmente teria se tornado científica. A complexidade do objeto, a subjetividade, o sentido, etc., para utilizar uma linguagem dos tempos atuais, seriam apenas casualties dessa busca de cientificidade.

O problema da comorbidade aponta, também, para um elemento da tradição médica que se encontra profundamente arraigado no pensamento psiquiátrico: o pressuposto de que existiriam entidades nosológicas discretas, cujos limites entre si e com a normalidade seriam nítidos. Nessa concepção realista, o desafio é fazer com que nossos conceitos (categorias diagnósticas) coincidam ponto a ponto com a natureza. Como nem a caracterização sintomatológica nem a prognóstica aparentemente corroboram tal concepção, posto que a variação contínua se afigura antes como regra, é compreensível que se apostem as fichas na elucidação patofisiológica e etiológica dos transtornos. Mas os desafios são múltiplos, uma vez que encontramos na medicina exemplos tanto de casos em que o conhecimento etiopatogênico (bioquímico e molecular) conta muito (Diabetes mellitus e Aids), como de outros em que este importa bem menos (Fibrose cística e Lúpus eritematoso sistêmico). Kenneth Schaffner (2002) abordou com propriedade esse tema no artigo "Clinical and etiological psychiatric diagnoses: do causes count?”, do qual foram extraídos os exemplos acima e onde podemos encontrar uma introdução clara sobre a questão da pluralidade das causas e dos modelos teóricos para cadeias causais complexas. ${ }^{3}$

Ainda que exista uma grande expectativa por parte de alguns profissionais de que a neutralidade etiológica seja abandonada já na próxima revisão dos sistemas CID e DSM, com a mudança de ênfase das descrições psicopatológicas

3. Deve-se ressaltar, ainda, a defesa que Schaffner faz da pertinência para a psiquiatria do modelo desenvolvido por Mackie para lidar com etiologia inespecífica, utilizando o que ele chamou de condições INUS, acrônimo para innsufficient but nonredundant part of an unnecessary but sufficient condition. Não é possível aqui explicar tal modelo, mas é importante sugerir algumas de suas vantagens potenciais: articulação entre elementos de diferentes tipos, efeitos e graus de influência causal (em ambas as direções, o que tornaria viável incluir, em termos nosológicos, também os fatores de proteção). Remeto o leitor interessado à excelente análise original de J.L. Mackie, publicada originalmente no artigo "Causes and conditions” (American Philosophical Quarterly, v. 2, n. 4, p. 245-64, 1965) e retomada depois no livro The Cement of the Universe (Oxford: Clarendon Press, 1974). 
para determinantes etiopatogênicos, há boas razões para se manter uma atitude de prudência cética. Em primeiro lugar, em que pesem os avanços da genética e das neurociências, nada nos autoriza a pensar que as estratégias bem-sucedidas no caso da doença de Huntington (e promissoras na doença de Alzheimer) tenham êxito no caso da esquizofrenia (para tomar como exemplo um transtorno central da psiquiatria). Além disso, a complexidade da questão da interação entre genes e ambiente ${ }^{4}$ constituir-se-ia, nas palavras de Kenneth Schaffner, num verdadeiro pesadelo científico. ${ }^{5}$ Assim, parece um tanto quanto prematuro supor que os conhecimentos disponíveis possam fornecer o princípio classificatório básico dos novos sistemas diagnósticos (CID-11 e DSM-V). Nada impede que se tente, no entanto, incluir uma classificação suplementar de elementos etiológicos ou de vias patofisiológicas comuns. Aliás, algo similar foi proposto há mais de meio século pelos pioneiros do diagnóstico multiaxial, Essen-Möeller \& Wohlfahrt (1947): eles procuravam evitar a confusão causada pela mistura inadvertida de princípios classificatórios descritivos e etiológicos, preconizando para tanto a utilização de eixos separados, cada qual com seu próprio princípio classificatório. Os principais objetivos dessa estratégia taxonômica seriam permitir o teste empírico da força de múltiplas associações, afastando ao mesmo tempo a falsa impressão de conhecimento proporcionada por soluções negociadas que, com freqüência, se cristalizam e terminam por prejudicar o desenvolvimento científico da disciplina. ${ }^{6}$

Entretanto, mesmo que as dificuldades arquiteturais de uma classificação de base etiológica possam ser contornadas de modo a preservar a complexidade das cadeias causais e que isso represente um ganho em termos de validade nosológica e diagnóstica (isto é, que corrobore tanto a existência do transtorno como nossa capacidade de identificá-lo), nada assegura que sua utilidade clínica venha a superar a dos sistemas atuais. Claro, é bastante razoável esperar que esclarecimentos etiopatogênicos contribuam para a melhora da atenção clínica,

4. As pesquisas recentes mostram que os genes respondem à experiência, assim deveríamos renunciar à idéia profundamente arraigada de que somos em parte produto da genética e em parte do ambiente, substituindo-a por uma outra fórmula: somos inteiramente produto dos genes $e$ inteiramente produto do ambiente.

5. Comentário feito durante a apresentação de seu paper "Ethical issues in behavioral genetics" durante o simpósio presidencial Moral and Philosophical Issues in Psychiatry, no encontro anual da Associação Psiquiátrica Norte-americana, realizado em 19 de maio de 2003, na cidade de São Francisco, EUA.

6. Analiso as questões relativas ao diagnóstico multiaxial em outro lugar: Cláudio E. M. Banzato, "Multiaxial diagnosis in psychiatry: review of the literature on DSM and ICD multiaxial schemas”, trabalho aceito para publicação no Jornal Brasileiro de Psiquiatria. 
afinal a história da medicina fornece incontáveis exemplos que dão suporte a tal expectativa. Mas o ponto aqui é outro: assim como, em princípio, os validadores externos de um transtorno podem simplesmente não coincidir, o que nos coloca o espinhoso problema de estabelecer uma hierarquia entre eles, é preciso admitir a hipótese de que validade e utilidade ${ }^{7}$ não estejam necessariamente atreladas.

Outra questão polêmica a ser enfrentada pelos autores dos próximos sistemas diagnósticos é a da manutenção ou não do critério de significância clínica, ponto em que a CID e o DSM explicitamente divergem. De fato, não parece muito lógico contar para fins diagnósticos com as possíveis conseqüências, em termos de perturbações ou limitações provocadas, das doenças (ou transtornos). Embora esta cláusula procure estabelecer um limiar, tentando separar os transtornos dos encargos cotidianos, ela sofre de uma certa circularidade, uma vez que a significância clínica deveria antes ser esclarecida pela própria definição do transtorno. Além disso, exclui-se de consideração sintomas mais leves que podem ser relevantes no contexto do tratamento, tanto em termos de uma detecção mais precoce de recaídas como de parâmetro para a avaliação do êxito terapêutico (por exemplo, sintomas residuais). ${ }^{8}$ Finalmente, a confusão do transtorno com suas conseqüências introduz um viés em favor dos casos mais severos, o que pode distorcer os resultados das pesquisas. Tais efeitos se assemelham àqueles produzidos pelo critério de duração, que afeta, principalmente, os estudos longitudinais. Essa discussão também é crucial para um tema que começa a ganhar destaque no cenário psiquiátrico: os diagnósticos e, sobretudo, as intervenções precoces, fundamentalmente probabilísticos, isto é, baseados na identificação e manipulação (tratamento) de supostos fatores de risco.

Há diversos outros tópicos pertinentes à elaboração de novos sistemas diagnósticos que mereceriam ser abordados, como a articulação de elementos nomotéticos e idiográficos e a necessidade de contemplar as diversas matrizes culturais, para ficar apenas com dois exemplos marcantes. De todo modo, escolhi para finalizar este artigo um ponto que está no cerne, penso, de tais questões. Ei-

7. A noção de "utilidade" mereceria uma discussão à parte. Vale lembrar que o termo "utilidade", aqui, está sendo empregado em sentido amplo, isto é, utilidade em vista dos mais variados propósitos a que se prestam as classificações diagnósticas, para seus diversos usuários.

8. Este aspecto é ressaltado pelos proponentes do modelo de "espectro", no qual os sintomas subliminares desempenham um papel mais relevante. O leitor interessado na noção de "espectro", que se aproxima de uma perspectiva dimensional (os sintomas variando num continuum), pode consultar o artigo: Jack D. Maser \& Thomas Patterson, "Spectrum and nosology: implications for DSM-V”, Psychiatric Clinics of North America, 25, p. 855-85, 2002. 
lo: é freqüente encontrar no debate psiquiátrico duas posições antagônicas sobre o estatuto ontológico dos transtornos mentais, contrapõem-se as concepções que tomam os transtornos como "tipos naturais" (natural kinds) e aquelas que os consideram “categorias arbitrárias” (ou convencionais). Não é difícil imaginar as implicações morais que, via de regra, acompanham as posições realistas e antirealistas no embate recorrente sobre a legimitidade da psiquiatria. Talvez, um conceito introduzido pelo filósofo Ian Hacking (1995 e 1999) ofereça uma alternativa para contornar tal impasse. Esse autor, utilizando a personalidade múltipla para estudar a constituição das ciências da memória, mostra que as pessoas reagem à maneira pela qual são classificadas, mas que, ao contrário do que a teoria da rotulação (labeling) postulava, essa reação não é necessariamente previsível (isto é, não se dá apenas no sentido esperado). A influência pode se revelar mais profunda, na medida em que classificações e nomenclaturas funcionam como sistemas simbólicos que, em última instância, conformam a experiência subjetiva e terminam por modificar o objeto classificado. Assim, Hacking propõe, para os casos em que tal fenômeno de looping é observado (aliás, recorrentes nos affairs humanos), o conceito de "tipo interativo" (interactive kind). Uma de suas vantagens é que ele permite escapar dessa armadilha do debate em torno do realismo. Outro benefício é proporcionar uma explicação convincente para o fato de algumas classificações (como a dos transtornos mentais) serem intermináveis, posto que tentam capturar alvos que se movem e se transformam ao longo do tempo.

Entender que as classificações diagnósticas funcionam como instrumentos provisórios é crucial para sua efetiva utilização. Penso, com Leighton (1986), que de uma atitude crítica dependa o futuro da psiquiatria: "Life, it seems, is mostly unfinished business, and so the task of keeping psychiatry sane remains still to be done.” Não é uma tarefa pequena.

\section{Referências}

Essen-Möeller, Eric \& Wohlfahrt, Snorre. Suggestions for the amendment of the official Swedish classification of mental disorders. Acta Psychiatrica Scandinavica, Supplement 47, p. 551-5, 1947.

Hacking, Ian. Rewriting the Soul. Princeton: Princeton University Press, 1995.

The Social Construct of What? Cambridge, Massachusetts: Harvard University Press, 1999.

Hyman, Steve E. Diagnosing disorders. Scientific American, v. 289. n. 3, p. 96-100, September, 2003. 


\section{O BSERVANDO A \\ PSIQ UIATRIA \\ ano VII, n. 1, mar/ 2004}

JABLENSKY, Assen. Beyond ICD-10 and DSM-IV: issues in contemporary psychiatry. In: Girolamo, Giovanni de et. al. (eds.). Promoting Mental Health Internationally. London: Gaskell, 1999. p. 47-56.

JASPERS, Karl. Psicopatologia Geral. Rio de Janeiro/São Paulo: Livraria Atheneu, 1987.

Leighton, Alexander H. Preface. Psychological Medicine, Monogr. Suppl., 10, p. 12, 1986.

Pouncey, Claire L. A Commentary on Psychiatric Diagnosis and Classification: A Conceptual Asymmetry. World Psychiatric Association, Classification Section's Newsletter, August, 2003. (http://www.wpanet.org/sectorial/section9.html). Acesso em: 14 jan. 2004.

Schaffner, Kenneth F. Clinical and Etiological Psychiatric Diagnoses: Do Causes Count? In: SAdler, John Z. (ed.). Descriptions and Prescriptions - Values, Mental Disorders, and the DSMs. Baltimore, Maryland: The Johns Hopkins University Press, 2002. p. 271-90.

SHEPHERD, Michael. A representative psychiatrist: the career, contributions and legacies of Sir Aubrey Lewis. Psychological Medicine, Monogr. Suppl., 10, p. 4-31, 1986.

Versão inicial recebida em janeiro de 2004

Versão revisada recebida em fevereiro de 2004 